\title{
Primary lateral sclerosis
}

INSERM

\section{Source}

INSERM. (1999). Orphanet: an online rare disease and orphan drug data base. Primary

lateral sclerosis. ORPHA:35689

Primary lateral sclerosis (PLS) is an idiopathic non-familial motor neuron disease

characterized by slowly progressive upper motor neuron dysfunction leading to spasticity, mild weakness in voluntary muscle movement, hyperreflexia, and loss of motor speech production. 